\title{
Effects of Breast-Conserving Surgery and Modified Radical Mastectomy on Early Breast Cancer
}

\author{
WEN YUN, JUNYING ZHANG, J. H. TANG ${ }^{1}$ AND Z. M. ZHOU²*
}

The Affiliated Cancer Hospital of Nanjing Medical University, Nanjing, Jiangsu 210009, ${ }^{1}$ Department of General Surgery, The First Affiliated Hospital of Nanjing Medical University, ${ }^{2}$ Department of Histology and Embryology, Nanjing Medical University, Nanjing, Jiangsu 210029, China

Yun et al.: Effects of Breast-Conserving Surgery and Modified Radical Mastectomy

\begin{abstract}
To compare the effects of breast-conserving surgery and modified radical mastectomy on early breast cancer is the objective of the study. $\mathbf{3 0}$ early breast cancer patients undergoing breast-conserving surgery and 30 cases undergoing modified radical mastectomy from January 2019 to February 2020 were selected. Their clinical data were retrospectively analyzed. Their operation conditions, postoperative pain score, immune function indices, incidence rate of postoperative complications, postoperative incision healing time, length of stay, excellent/good rate of breast appearance and quality of life score were compared. The rate of positive resection margin and operation time had no statistically significant differences between the two groups $(p>0.05)$. In breast-conserving group, the intraoperative blood loss was smaller $(p<0.05)$ and the postoperative incision healing time and length of stay were shorter than those in radical mastectomy group $(p<0.05)$. The pain scores at 1-3 d after operation significantly declined in breast-conserving group compared with those in radical mastectomy group $(p<0.05)$. After operation, the levels of cluster of differentiation $3^{+}$and cluster of differentiation 4/cluster of differentiation 8 significantly declined in both groups compared with those before operation, while they were higher in breast-conserving group than those in radical mastectomy group $(p<0.05)$. The incidence rate of postoperative complications in breast-conserving group was lower than that in radical mastectomy group $(3.33 \%$ vs. $20.00 \%)(p<0.05)$ and the excellent/good rate of breast appearance in breast-conserving group was higher than that in radical mastectomy group $(96.67 \% v s .76 .67 \%)(p<0.05)$. After operation, breast-conserving group had a higher quality of life score than that of radical mastectomy group $(\mathbf{p}<\mathbf{0 . 0 5})$. Both breast-conserving surgery and modified radical mastectomy can remove tumor lesions in patients with early breast cancer. However, breast-conserving surgery is superior in decreasing intraoperative blood loss, facilitating postoperative rehabilitation, relieving postoperative pain, protecting immune function and reducing postoperative complications, thereby improving quality of life of patients.
\end{abstract}

Key words: Breast cancer, breast-conserving surgery, modified radical mastectomy, quality of life score

Breast cancer is a common malignancy with the highest morbidity rate in females, seriously impairing their physical and mental health ${ }^{[1,2]}$. Early treatment is advocated clinically for breast cancer, the first choice of which is surgery. Traditional radical mastectomy is commonly used to effectively remove breast tumors ${ }^{[3,4]}$. With the increasingly higher requirement of female patients for aesthetics, however, modified radical mastectomy and breast-conserving surgery have been gradually applied in the treatment of breast cancer, which can reduce surgical trauma compared with traditional radical mastectomy ${ }^{[5]}$. However, the breast aesthetics after modified radical mastectomy and the effectiveness of breast-conserving surgery in breast cancer resection remain to be explored. To solve this problem, 30 early breast cancer patients undergoing breast-conserving surgery and 30 cases undergoing modified radical mastectomy in our hospital from January 2019 to February 2020 were selected to clarify the effects of the two surgical procedures on early breast cancer.

\section{MATERIALS AND METHODS}

\section{General data:}

A total of 30 early breast cancer patients undergoing breast-conserving surgery (breast-conserving group) and 30 cases undergoing modified radical mastectomy (radical mastectomy group) in our hospital from January 2019 to February 2020 were selected as the subjects. The clinical data of patients were retrospectively analyzed. In breast-conserving group, the patients were aged 35-67 y old, with an average age of $(50.42 \pm 13.85)$

*Address for correspondence

E-mail: zhouzm@njmu.edu.cn 
$y$ old and there were 25 cases of stage I and 5 cases of stage IIA. In radical mastectomy group, the female patients were aged 34-69 y old, with an average of $(50.93 \pm 13.72)$ y old. There were 26 cases of stage I and 4 cases of stage IIA. Age, tumor stage and gender had no significant differences between the two groups $(\mathrm{p}>0.05)$.

Inclusion criteria were as follows. Patients pathologically diagnosed as stage I-IIA breast cancer by imaging examination and biopsy before operation, without lymph node metastasis; those with indications for radical mastectomy and breast-conserving surgery; those who were informed of the operation and signed the informed consent before operation; those with an estimated survival time $>3$ mo and those with complete clinical data.

Exclusion criteria were as follows. Patients complicated with other malignancies; those complicated with severe infections or coagulation dysfunction; those complicated with chronic underlying diseases such as diabetes and hypertension, or those with a history of thoracic operation.

In breast-conserving group, breast-conserving surgery was conducted. After general anesthesia by tracheal intubation, the position of breast cancer lesions was marked on the body surface in a supine position and an arc-shaped incision was made at the marking point to remove the primary lesions, with resection margin at $2 \mathrm{~cm}$ away from the tumor. Moreover, a small incision was made under the axilla along the dermatoglyph and the lymph nodes were dissected from the anterior edge of the latissimus dorsi muscle to the deep pectoralis minor muscle. Finally, the incision was sutured.

In radical mastectomy group, modified radical mastectomy was conducted. After general anesthesia by tracheal intubation, a surgical incision was designed (at least $3 \mathrm{~cm}$ away from the resection margin) in a supine position based on the position of breast cancer lesions. The skin and subcutaneous tissue were cut open layer by layer, and the mammary gland and deep pectoralis major fascia were separated upwards below the lateral border of the pectoralis major muscle, followed by lymph node dissection among pectoralis major muscles. The mammary gland was tightened outwards, and the pectoralis major and pectoralis minor muscles were pulled inwards and separated longitudinally along the boundary of lateral border of the pectoralis major muscle and mammary gland. Then the pectoralis minor muscle was lifted to expose the axillary blood vessels, followed by axillary lymph node dissection.
The pectoralis major muscle, pectoralis minor muscle, anterior thoracic nerve and intercostobrachial nerve were preserved, then the surgical wound was washed and the drainage tube was indwelt. Finally, the incision was sutured.

\section{Observation indices:}

The operation conditions (rate of positive resection margin, operation time and intraoperative blood loss), postoperative pain score, immune function indices (Cluster of Differentiation $3^{+}\left(\mathrm{CD}^{+}\right)$and Cluster of Differentiation 4 (CD4)/Cluster of Differentiation 8 (CD8) before operation and at $3 \mathrm{~d}$ after operation), incidence rate of postoperative complications, postoperative incision healing time, length of stay, excellent/good rate of breast appearance and Quality of Life (QOL) score were compared between the two groups.

Pain scores were as follows. At 1, 2 and $3 \mathrm{~d}$ after operation, the Visual Analogue Scale (VAS) score was given. It ranges from 0 (no pain) to 10 points (severe pain) and the higher the score, the severer the pain.

Assessment criteria for breast appearance were as follows ${ }^{[6]}$.

Excellent: The breasts on both sides are symmetrical without obvious difference in appearance and the horizontal distance between the two nipples is $<2 \mathrm{~cm}$.

Good: The breast of the affected side is slightly smaller than that of the other side and the horizontal distance between the two nipples is $\geq 2 \mathrm{~cm}$ but $<3 \mathrm{~cm}$.

Poor: The breasts on both sides are asymmetrical and the horizontal distance between the two nipples reaches $3 \mathrm{~cm}$. Excellent $/$ good rate $=$ excellent rate + good rate.

QOL score-World Health Organization Quality of Life Scale Brief Version (WHOQOL-BREF) was used for assessment before operation and at $3 \mathrm{~d}$ after operation. The scale consists of physical domain, psychological domain, environmental domain and social relation, and the score ranges from 0 to 100 points, the higher the score, the better the QOL ${ }^{[7]}$.

\section{Statistical analysis:}

Statistical Package for the Social Sciences (SPSS) 22.0 software was used. Numerical data were expressed as $\mathrm{n}$ $(\%)$ and the $\chi^{2}$ test was performed. Measurement data were expressed as $(\overline{\mathrm{x}} \pm \mathrm{s})$, the paired t test was performed for intragroup comparison and the independent-samples $t$ test was conducted for intergroup comparison, $p<0.05$ was considered statistically significant. 


\section{RESULTS AND DISCUSSION}

The rate of positive resection margin and operation time had no statistically significant differences between the two groups $(p>0.05)$. In breast-conserving group, the intraoperative blood loss was smaller $(p<0.05)$, and the postoperative incision healing time and length of stay were shorter than those in radical mastectomy group $(\mathrm{p}<0.05)$ (Table 1).

Postoperative pain scores were described below. The pain scores at 1-3 d after operation significantly declined in breast-conserving group compared with those in radical mastectomy group $(\mathrm{p}<0.05)$ (Table 2$)$.

Immune function indices were explained in detail. After operation, the levels of $\mathrm{CD}^{+}$and $\mathrm{CD} 4 / \mathrm{CD} 8$ significantly declined in both groups compared with those before operation $(\mathrm{p}<0.05)$, while they were higher in breast-conserving group than those in radical mastectomy group $(\mathrm{p}<0.05)$ (Table 3$)$.

The incidence rate of postoperative complications in breast-conserving group was lower than that in radical mastectomy group $(3.33 \%$ vs. $20.00 \%) \quad(\mathrm{p}<0.05)$ (Table 4).

The excellent/good rate of breast appearance in breastconserving group was higher than that in radical mastectomy group $(96.67 \%$ vs. $76.67 \%)(\mathrm{p}<0.05)$ (Table 5).

After operation, the QOL score significantly rose in the two groups compared with that before operation $(p<0.05)$, and breast-conserving group had a higher QOL score than radical mastectomy group $(\mathrm{p}<0.05)$ (Table 6).

TABLE 1: OPERATION CONDITIONS, POSTOPERATIVE INCISION HEALING TIME AND LENGTH OF STAY

\begin{tabular}{lccccc}
\hline Group & $\mathrm{n}$ & $\begin{array}{c}\text { Rate of positive } \\
\text { resection } \\
\text { margin }\end{array}$ & $\begin{array}{c}\text { Operation time } \\
(\text { min) }\end{array}$ & $\begin{array}{c}\text { Intraoperative } \\
\text { blood loss }(\mathrm{ml})\end{array}$ & $\begin{array}{c}\text { Postoperative } \\
\text { incision healing } \\
\text { time }(\mathrm{d})\end{array}$ \\
\hline $\begin{array}{l}\text { Radical } \\
\text { mastectomy }\end{array}$ & 30 & $1(3.33 \%)$ & $59.47 \pm 15.42$ & $84.65 \pm 21.87$ & $15.54 \pm 2.68$ \\
$\begin{array}{l}\text { Breast- } \\
\text { conserving } \\
\text { surgery }\end{array}$ & 30 & $2(6.67 \%)$ & $58.28 \pm 16.29$ & $30.27 \pm 8.15^{*}$ & $12.87 \pm 2.19^{*}$ \\
\hline
\end{tabular}

Note: ${ }^{*} \mathrm{p}<0.05$ vs. radical mastectomy group

TABLE 2: POSTOPERATIVE PAIN SCORES $(\overline{\mathbf{x}} \pm \mathbf{s}$, POINT)

\begin{tabular}{lccc}
\hline \multirow{2}{*}{ Group } & \multicolumn{3}{c}{ Pain score } \\
\cline { 2 - 4 } & 1 d after operation & 2 d after operation & 3 d after operation \\
\hline Radical mastectomy $(n=30)$ & $4.52 \pm 1.07$ & $3.74 \pm 0.81$ & $2.95 \pm 0.78$ \\
Breast-conserving $(n=30)$ & $3.46 \pm 0.91^{*}$ & $2.79 \pm 0.74^{*}$ & $2.10 \pm 0.67^{*}$ \\
\hline
\end{tabular}

Note: ${ }^{*} \mathrm{p}<0.05$ vs. radical mastectomy group

TABLE 3: IMMUNE FUNCTION INDICES $(\overline{\mathbf{x}} \pm \mathbf{s})$

\begin{tabular}{lccc}
\hline Group & Time & CD3 ${ }^{+}(\%)$ & CD4/CD8 \\
\hline Radical mastectomy $(n=30)$ & Before operation & $45.43 \pm 2.91$ & $1.71 \pm 0.32$ \\
& After operation & $39.12 \pm 2.57^{\#}$ & $1.16 \pm 0.25^{\#}$ \\
Breast-conserving $(\mathrm{n}=30)$ & Before operation & $45.61 \pm 2.86$ & $1.74 \pm 0.31$ \\
& After operation & $41.84 \pm 2.65^{\# *}$ & $1.43 \pm 0.27^{\# *}$ \\
\hline
\end{tabular}

Note: ${ }^{\#} \mathrm{p}<0.05$ vs. the same group before operation, ${ }^{*} \mathrm{p}<0.05$ vs. radical mastectomy group

TABLE 4: INCIDENCE RATES OF POSTOPERATIVE COMPLICATIONS [n (\%)]

\begin{tabular}{|c|c|c|c|c|c|}
\hline Group & $\mathrm{n}$ & $\begin{array}{l}\text { Upper limb } \\
\text { lymphedema }\end{array}$ & $\begin{array}{c}\text { Axillary lymphatic } \\
\text { leakage }\end{array}$ & Incision infection & $\begin{array}{c}\text { Total incidence } \\
\text { rate }\end{array}$ \\
\hline $\begin{array}{l}\text { Radical } \\
\text { mastectomy }\end{array}$ & 30 & $3(10.00 \%)$ & $2(6.67 \%)$ & $1(3.33 \%)$ & $6(20.00 \%)$ \\
\hline Breast-conserving & 30 & $1(3.33 \%)$ & $0(0 \%)$ & $0(0 \%)$ & $1(3.33 \%)^{*}$ \\
\hline
\end{tabular}

Note: ${ }^{*} \mathrm{p}<0.05$ vs. radical mastectomy group 
www.ijpsonline.com

TABLE 5: EXCELLENT/GOOD RATES OF BREAST APPEARANCE [n (\%)]

\begin{tabular}{lccccc}
\hline Group & $\mathrm{n}$ & Excellent & Good & Poor & $\begin{array}{c}\text { Excellent/good } \\
\text { rate }\end{array}$ \\
\hline $\begin{array}{l}\text { Radical } \\
\text { mastectomy }\end{array}$ & 30 & $13(43.33 \%)$ & $10(33.33 \%)$ & $7(23.33 \%)$ & $23(76.67 \%)$ \\
Breast-conserving & 30 & $17(56.67 \%)$ & $12(40.00 \%)$ & $1(3.33 \%)$ & $29(96.67 \%)^{*}$ \\
\hline
\end{tabular}

Note: ${ }^{*} \mathrm{p}<0.05$ vs. radical mastectomy group

TABLE 6: QOL SCORES ( $\overline{\mathbf{x}} \pm \mathbf{s}$, POINT)

\begin{tabular}{lccccc}
\hline Group & Time & Physical domain & $\begin{array}{c}\text { Psychological } \\
\text { domain }\end{array}$ & $\begin{array}{c}\text { Environmental } \\
\text { domain }\end{array}$ & Social relation \\
\hline $\begin{array}{l}\text { Radical } \\
\text { mastectomy }(\mathrm{n}=30)\end{array}$ & Before operation & $70.75 \pm 5.14$ & $70.34 \pm 5.18$ & $70.27 \pm 5.04$ & $70.39 \pm 5.12$ \\
& After operation & $78.34 \pm 5.82^{\#}$ & $79.07 \pm 5.46^{\#}$ & $77.16 \pm 5.23^{\#}$ & $77.65 \pm 5.30^{\#}$ \\
$\begin{array}{l}\text { Breast-conserving } \\
(\mathrm{n}=30)\end{array}$ & Before operation & $70.96 \pm 5.17$ & $70.45 \pm 5.13$ & $70.48 \pm 5.09$ & $70.20 \pm 5.16$ \\
& After operation & $84.05 \pm 5.59^{\# *}$ & $84.39 \pm 5.28^{\# *}$ & $83.47 \pm 5.93^{\# *}$ & $83.62 \pm 5.71^{\# *}$ \\
\hline
\end{tabular}

Note: ${ }^{\#} p<0.05$ vs. the same group before operation, ${ }^{*} p<0.05$ vs. radical mastectomy group

Breast cancer, a malignancy with the highest morbidity rate in females, has exhibited increasing incidence in recent years. In China, breast cancer accounts for about $7-10 \%$ of malignancies and its morbidity rate ranks first in female malignancies, seriously harming the healthy life of females ${ }^{[8-10]}$. Therefore, active and effective treatment is clinically advocated for breast cancer to control the progression.

Breast cancer can be radically cured by surgery only ${ }^{[11]}$. Traditional radical mastectomy completely removes tumor lesions and lowers the risk of distant metastasis primarily through resecting mammary tissues and pectoralis major muscles, but it causes great trauma to the body, affecting the postoperative recovery of patients ${ }^{[12]}$. Recently, with the increasingly higher requirement of females for aesthetics, breast cancer patients will not only express requirements for surgical effect, but also demand to preserve the breast appearance as much as possible. In this context, modified radical mastectomy and breast-conserving surgery have been gradually applied in the treatment of breast cancer ${ }^{[13]}$. In modified radical mastectomy, the resection range is adjusted, and both anterior thoracic nerve and intercostobrachial nerve of patients are preserved, thereby reducing the resection range to a certain extent and relieving the surgical trauma to the body. In breast-conserving surgery, the breast tumor is resected mainly based on its position, so that the resection range is greatly reduced, the breast is effectively preserved and indiscriminate expansion of the partial resection range is avoided, thereby better retaining the breast aesthetics. At the same time, surgical trauma is relieved, postoperative recovery is better promoted and postoperative breast scars are reduced, further enhancing postoperative breast aesthetics and increasing patient's self-confidence ${ }^{[14]}$.

The effectiveness of modified radical mastectomy in breast cancer patients and the ability of breastconserving surgery to retain the breast aesthetics of patients have been recognized clinically, but whether the short-term efficacy of breast-conserving surgery can be comparable to that of modified radical mastectomy remains controversial. To solve this problem, two groups of breast cancer patients were selected for retrospective comparison in the present study. It was found that the rate of positive resection margin and operation time had no statistically significant differences between the two groups $(\mathrm{p}>0.05)$. In breast-conserving group, the intraoperative blood loss was smaller $(\mathrm{p}<0.05)$, and the postoperative incision healing time and length of stay were shorter than those in radical mastectomy group $(\mathrm{p}<0.05)$. The postoperative pain score and incidence rate of postoperative complications were significantly lower in breast-conserving group than those in radical mastectomy group $(\mathrm{p}<0.05)$. After operation, the levels of $\mathrm{CD}^{+}$and $\mathrm{CD} 4 / \mathrm{CD} 8$ significantly declined in both groups compared with those before operation $(p<0.05)$, while they were higher in breast-conserving group than those in radical mastectomy group $(p<0.05)$. The above findings suggest that compared with modified radical mastectomy, breast-conserving surgery can further reduce the surgical trauma, lower the risk of postoperative complications and alleviate the physical 
pain and immune function impairment of patients. The excellent/good rate of breast appearance in breastconserving group was higher than that in radical mastectomy group $(96.67 \%$ vs. $76.67 \%)(\mathrm{p}<0.05)$, indicating that breast-conserving surgery can better preserve the breast appearance. The main reason is that breast-conserving surgery can reduce both breast resection range and surgical incision, so that it has fewer impacts on the breast appearance than modified radical mastectomy. After operation, breast-conserving group had a higher QOL score than radical mastectomy group ( $\mathrm{p}<0.05)$. The main reason is that after breastconserving surgery, there are few complications, the breast appearance is better and the patient's physical and mental discomfort is alleviated, thereby reducing the impact on the QOL.

In conclusion, both breast-conserving surgery and modified radical mastectomy can remove tumor lesions in patients with early breast cancer. However, breastconserving surgery is superior in reducing intraoperative blood loss, facilitating postoperative rehabilitation, relieving postoperative pain, protecting immune function and reducing postoperative complications, thereby improving the QOL of patients.

\section{Conflict of interests:}

The authors declared no conflict of interest.

\section{REFERENCES}

1. Khan JS, Hodgson N, Choi S, Reid S, Paul JE, Hong NJ, et al. Perioperative pregabalin and intraoperative lidocaine infusion to reduce persistent neuropathic pain after breast cancer surgery: a multicenter, factorial, randomized, controlled pilot trial. J Pain 2019;20(8):980-93.

2. Warschkow R, Güller U, Tarantino I, Cerny T, Schmied BM, Thuerlimann B, et al. Improved survival after primary tumor surgery in metastatic breast cancer: A propensityadjusted, population-based SEER trend analysis. Ann Surg 2016;263(6):1188-98.

3. Kuerer HM, Rauch GM, Krishnamurthy S, Adrada BE, Caudle AS, DeSnyder SM, et al. A clinical feasibility trial for identification of exceptional responders in whom breast cancer surgery can be eliminated following neoadjuvant systemic therapy. Ann Surg 2018;267(5):946-51.

4. Fasse L, Flahault C, Vioulac C, Lamore K, Van Wersch A, Quintard B, et al. The decision-making process for breast reconstruction after cancer surgery: Representations of heterosexual couples in long-standing relationships. $\mathrm{Br} \mathrm{J}$ Health Psychol 2017;22(2):254-69.

5. Qiu H, Xu WH, Kong J, Ding XJ, Chen DF. Effect of breast- conserving surgery and modified radical mastectomy on operation index, symptom checklist-90 score and prognosis in patients with early breast cancer. Medicine 2020;99(11):e19279.

6. Recio-Saucedo A, Gerty S, Foster C, Eccles D, Cutress RI. Information requirements of young women with breast cancer treated with mastectomy or breast conserving surgery: A systematic review. Breast 2016;25:1-13.

7. Bhat V, Roshini AP, Ramesh R. Does quality of life among modified radical mastectomy and breast conservation surgery patients differ? A 5-year comparative study. Indian J Surg Oncol 2019;10(4):643-8.

8. Kolberg HC, Loevey G, Akpolat-Basci L, Stephanou M, A Fasching $\mathrm{P}$, Untch $\mathrm{M}$, et al. Targeted intraoperative radiotherapy tumour bed boost during breast conserving surgery after neoadjuvant chemotherapy in HER2 positive and triple negative breast cancer. Rev Recent Clin Trials 2017;12(2):93-100.

9. Daugherty EC, Daugherty MR, Bogart JA, Shapiro A. Adjuvant radiation improves survival in older women following breastconserving surgery for estrogen receptor-negative breast cancer. Clin Breast Cancer 2016;16(6):500-6.

10. García-Ruano AA, Deleyto E, Lasso JM. First report of pyoderma gangrenosum after surgery of breast cancerrelated lymphedema with transfer of vascularized free lymph nodes of the groin and simultaneous DIEP flap. Breast Care 2016;11(1):57-9.

11. Greenup RA, Rushing C, Fish L, Campbell BM, Tolnitch L, Hyslop T, et al. Financial costs and burden related to decisions for breast cancer surgery. J Oncol Pract 2019;15(8):e666-76.

12. Plesca M, Bordea C, El Houcheimi B, Ichim E, Blidaru A. Evolution of radical mastectomy for breast cancer. J Med Life 2016;9(2):183-6.

13. Vishwakarma M, Sahani IS. Comparative study of complications of modified radical mastectomy and breast conservation therapy in early invasive breast cancer. Int J Surg 2019;3(1):1-3.

14. Jabłoński MJ, Streb J, Mirucka B, Słowik AJ, Jach R. The relationship between surgical treatment (mastectomy $v s$. breast conserving treatment) and body acceptance, manifesting femininity and experiencing an intimate relation with a partner in breast cancer patients. Psychiatr Pol 2018;52(5):859-72.

This is an open access article distributed under the terms of the Creative Commons Attribution-NonCommercial-ShareAlike 3.0 License, which allows others to remix, tweak, and build upon the work non-commercially, as long as the author is credited and the new creations are licensed under the identical terms

This article was originally published in a special issue, "Novel Therapeutic Approaches in Biomedicine and Pharmaceutical

Sciences" Indian J Pharm Sci 2021:83(6) Spl Issue "169-173" 